\title{
DERMATOSES IN THE MANUFACTURE OF GLASS FIBRE
}

\author{
BY \\ WILLIAM B. MCKENNA, J. F. FERGUSON SMITH, and DONALD A. MACLEAN \\ From the Department of Dermatology, Western Infirmary, Glasgow, and Fibreglass Limited, Glasgow Division
}

(RECEIVED FOR PUBLICATION MARCH 21, 1957)

Continuous filament glass fibre is used in the manufacture of glass yarn and textile products. It is made from either alkali or alkali-free glass. The main ingredients of alkali glass are sand, lime, dolomite, and soda ash; for alkali-free glass no raw materials containing alkali are used, and boric acid is an additional major constituent. There are two methods of manufacture. (a) The glass is fed straight to the fibre-forming furnaces from a direct melt tank; or $(b)$ it is made into solid glass marbles which are fed to the furnaces. The description which follows is confined to the manufacture of continuous filament by the latter process using alkali-free marbles.

\section{Materials and Manufacture}

The glass marbles are placed in hoppers from which they are mechanically fed to the furnaces. Each furnace consists of a sheet platinum crucible about 9 in. long, 5 in. wide, and 9 in. deep, with about 200 small holes in the bottom. The crucible is insulated by high temperature refractory material which leaves the bottom exposed; the crucible is electrically heated to about $1200^{\circ} \mathrm{C}$. which melts the glass. The molten glass, under gravity, drips through the holes in the bottom of the crucible and is drawn into fine filaments by being wound on to a high-speed winder. As they are formed, the filaments are sprayed with a fine mist of cold water and then treated with an emulsion from a constant feed jet as they converge to a felt-covered pad to form a single multi-filament strand.

The furnace is situated about 12 feet above ground level, but only 5 feet above an intermediate platform on which the operator stands. This intermediate floor or platform communicates with the ground level by an opening through which the glass fibre passes to the collecting tube which is placed on the high-speed winding head.

The nature of the emulsion applied to the filaments at the pad level varies according to the use to which the glass fibre is to be put.

Glass fibre for textile use is treated with an emulsion which forms a protective coating against abrasion and fracture during the twisting and doubling of the fibre in the course of processing. This emulsion, which is slightly acid ( $p \mathrm{H} 5 \cdot 7-6 \cdot 5)$ is applied at temperatures between $110^{\circ} \mathrm{F}$. and $130^{\circ} \mathrm{F}$., and contains the following ingredients:-

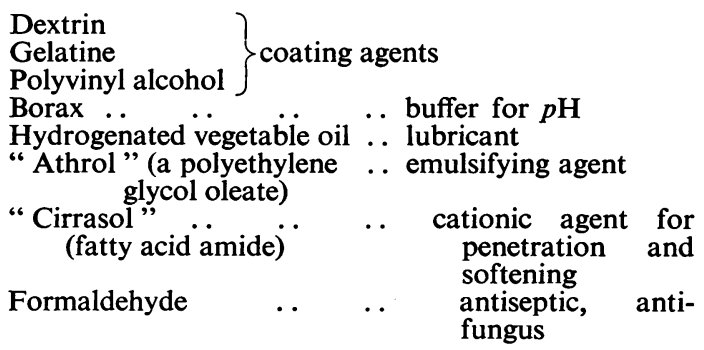

Glass fibre for the reinforcement of plastics is treated with an emulsion which will impart a protective coating and at the same time be suitable for further linking with phenolic and polyester resins and other media used in plastics. This compatibility is achieved by the addition of a " keying agent" to the emulsion. There are several varieties of emulsions, but the main ingredients are as follows:-

$$
\begin{aligned}
& \begin{array}{llll}
\text { Polyvinyl acetate } & \text {. } & \text {.. } & \text { coating agent }
\end{array} \\
& \text { Di-butyl-phthalate } \quad . \quad \ldots \quad \text { plasticiser } \\
& \text { "Cirrasol" } \quad . . \quad \ldots \quad \text {.. } \\
& \text { softener }
\end{aligned}
$$

This type of emulsion is applied cold at a temperature between $60^{\circ} \mathrm{F}$. and $75^{\circ} \mathrm{F}$.

\section{Environmental Conditions and Hazards}

Glass fibre manufacture is hot and wet, and the operators are exposed to a relatively humid atmo- 


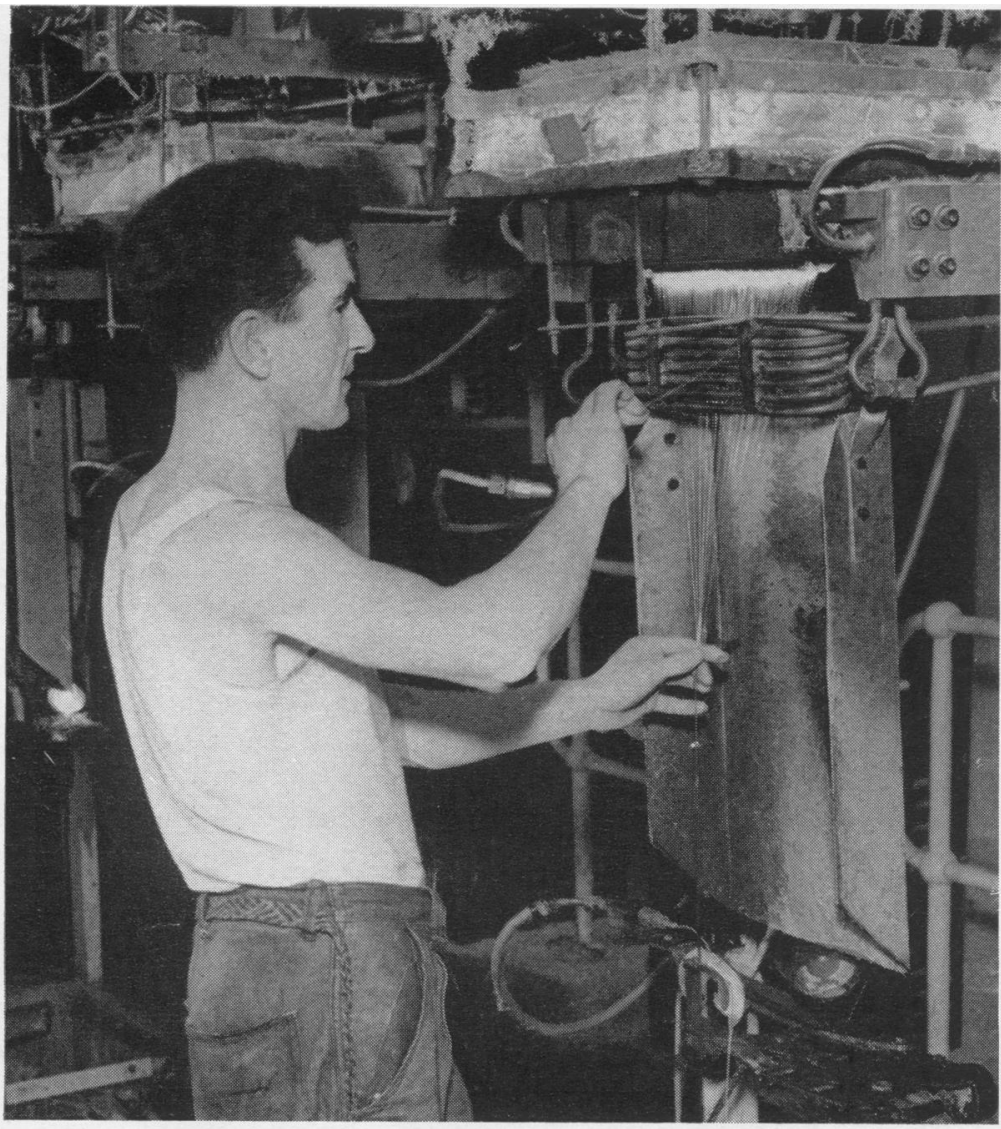

FIG. 1.-Operator in glass fibre manufacture.

sphere. The room temperature varies from $80^{\circ} \mathrm{F}$. to $90^{\circ} \mathrm{F}$., and the relative humidity from $60 \%$ to $70 \%$.

Operating and winding are the two main occupations in the manufacture of glass fibre. The work of the operator is illustrated in Fig. 1. He is in charge of a battery of furnaces and attends to faults in the glass as it issues from the crucible, and to breakages in the filament. In the course of his work, his hands are exposed to the radiant.heat from the base of the crucible and to burns from molten glass. He has to handle the relatively coarse fibres issuing from the crucible and is liable to puncture wounds of the hands and feet. His hands are also exposed to constant wetting from water and emulsion. The work of the winder who attends to the winding machine is illustrated in Fig. 2. He is not exposed to the radiant heat hazard of the operator, but he is exposed to the other hazards of the operator and more so to the water and emulsion which come off the water guard and emulsion pad to fall to ground level.
The other workers are floaters, who relieve the operators and winders as required, graders and checkers, who test the fibres for quality, and cleaners, who clean the working area other than the actual machines which are the responsibility of the operators and winders.

\section{Skin Lesions}

The nature of the substance being converted into fibre and the various agents applied to it in processing, together with the hot, humid and wet conditions in which the process is carried on, are such that the various operatives consider that dermatological risks are to be expected in this employment. As a result of this belief, they only seek treatment when they have an established dermatitis. In such cases it is often impossible to determine whether the skin condition is occupational or not.

It was observed by one of us (D. A. M.) that paronychia and abnormal nail formation of the fingers commonly occurred among the employees in the continuous filament department. It was 
thought that the condition might be due to a fungus infection of the skin and nails. All the employees in this department, a total of 126 males (60 winders, 51 operators, 13 checkers, one cleaner, and one fitter), were therefore asked to submit to a skin inspection, and all did so. It was found that in $63(50 \%)$ the skin of the toes in the fourth interdigital space was peeling, and that eight operators had paronychia and abnormal nail formation of the fingers. These findings were suggestive of a fungus infection, and as the conditions at work were conducive to spread of such infection, it was considered that the problem was one for the attention of a dermatologist with experience of conditions in industry.

\section{Investigation}

At the request of the management concerned, arrangements were therefore made to carry out a further dermatological survey of the 126 operatives in the continuous filament department. Particular attention was paid to feet, hands, and nails, and where there was clinical evidence suggestive of fungus infection, scrapings were taken for mycological investigation.

The findings are summarized in the table. Three

TABLE

RESULTS OF DERMATOLOGICAL SURVEY OF 126 EMPLOYEES IN CONTINUOUS FILAMENT DEPARTMENT

\begin{tabular}{l|c|c|c|c}
\hline & Fitters & Operators & Winders & Checkers \\
\hline Paronychia & - & 5 & 3 & - \\
Maceration & 1 & 25 & 32 & 5 \\
\hline Folliculitis & - & 2 & 12 & - \\
\hline No. of employees . & 1 & 51 & 60 & 13 \\
\hline
\end{tabular}

One cleaner had no abnormality of the skin

distinct clinical conditions were observed: paronychia, a "follicular eruption", and interdigital
Fig. 2.-Winder in glass fibre manufacture.

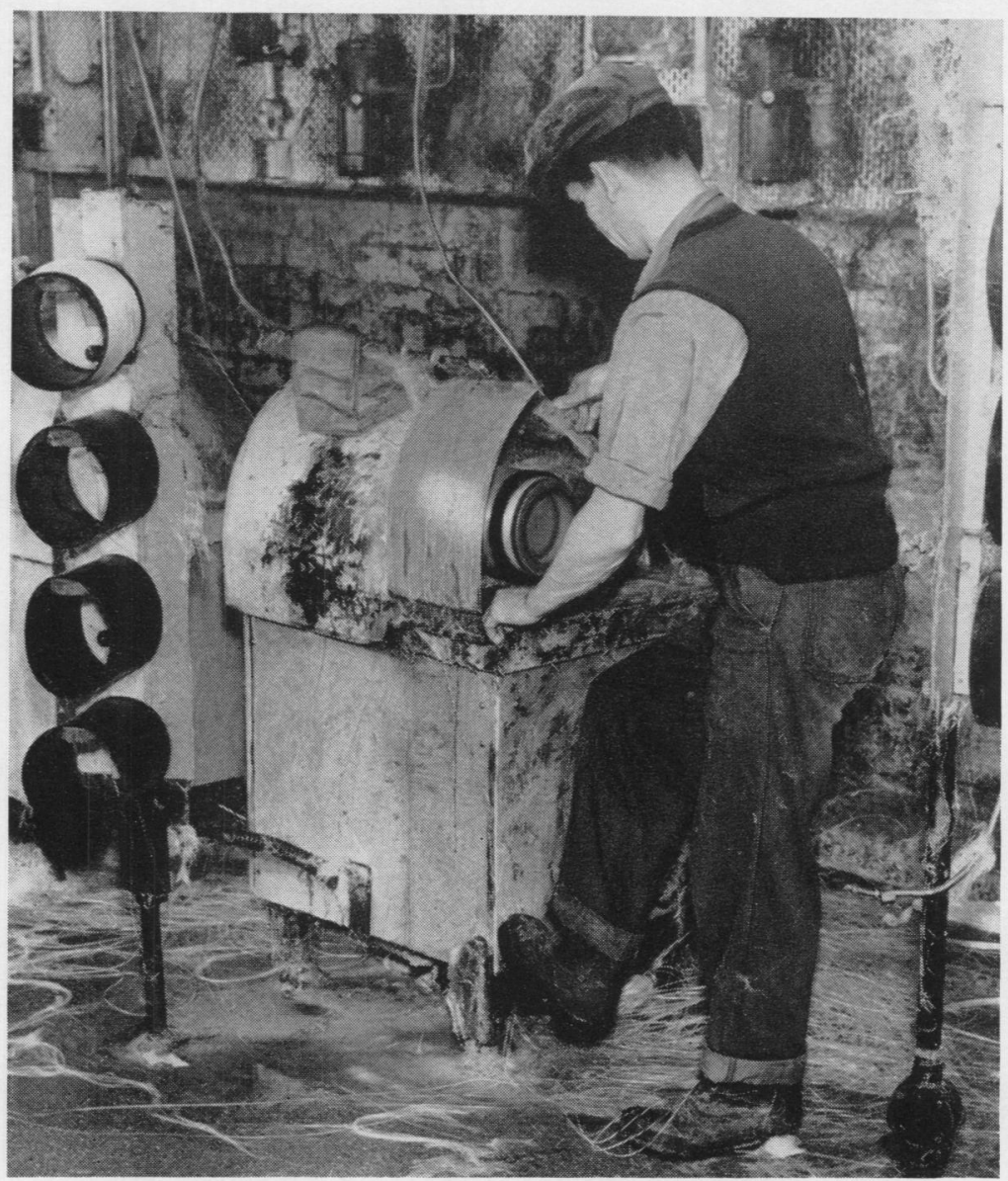


maceration of the feet. Each will be described separately.

Paronychia.-Out of 126 operatives examined, eight cases $(6.3 \%)$ of paronychia were observed. This condition involved the nail folds of one or more fingers, except in one case where the nail fold of the left great toe was affected, the inflammatory reaction being of a specific type. The nail fold was firm or indurated with minimal erythema and without the " bolstering" typical of pyogenic or yeast organism infections (Fig. 3). Tenderness was not a clinical feature and in only one case was there a history of pus formation. Secondary malformation of the nail was present in all eight cases, and in one onychorrhexis was complete. In spite of the clinical evidence of a low-grade inflammatory process the operative was not incapacitated. Direct and cultural mycological investigation in each case failed to reveal any specific pathogen. In three cases there was radiological evidence of glass spicules lying close to the nail fold in a site where clinical activity was at its maximum.

Folliculitis.-In 14 operatives $(11 \cdot 1 \%)$, we observed a fairly characteristic eruption involving the dorsum of the feet, lower third of the legs, forearms, and occasionally of the hands (Fig. 4). The lesions were in the main follicular in character, papular or papulo-pustular, not itchy, and dull red. In "susceptible" individuals the dermatosis was characterized by a period of exacerbation and complete remission unrelated to periods of work or

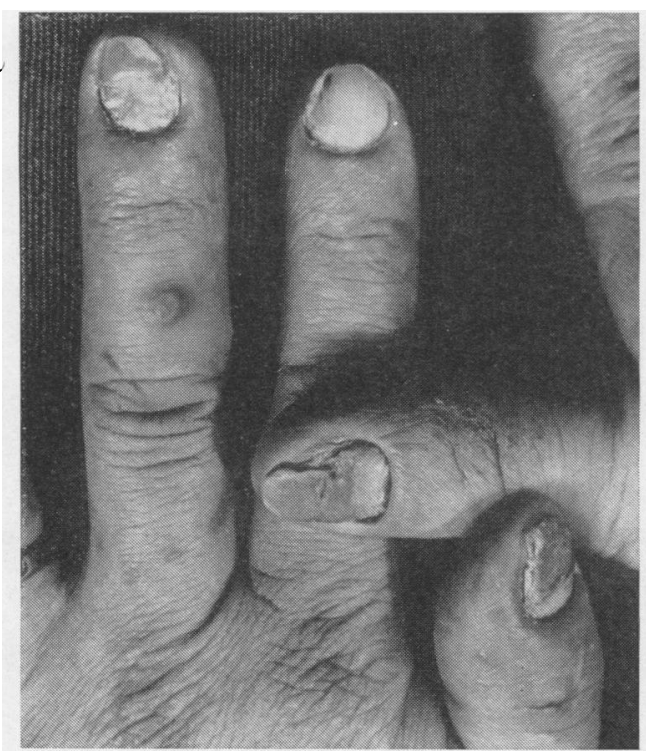

FIG. 3.-The inflammatory reaction of the nail folds with secondary nail malformation.

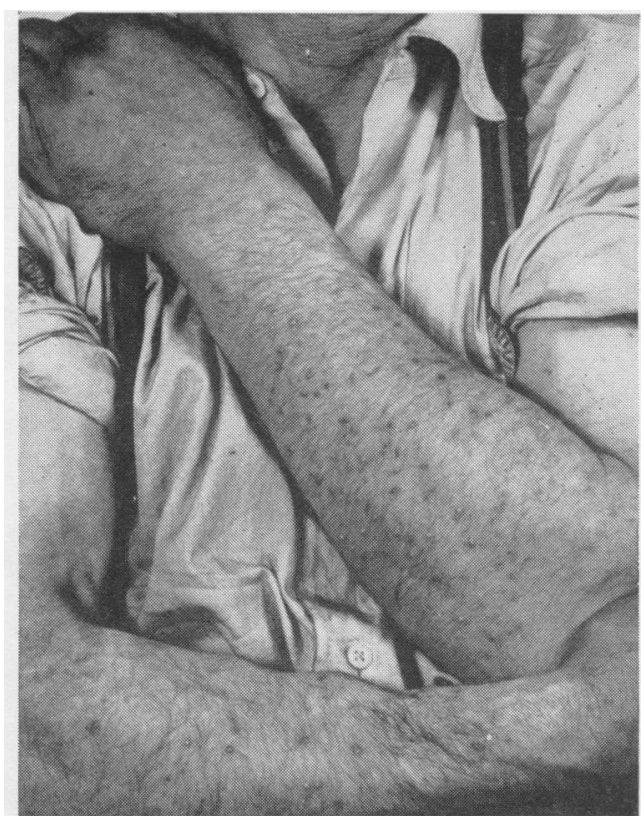

FIG. 4.-Marked follicular papulo-pustulation of the forearms.

holidays. Spontaneous involution occurred in all cases after a variable period. This eruption closely resembled the clinical picture of oil folliculitis observed in the engineering industry, and we suggest that this follicular reaction may have been produced by the hydrogenated vegetable oils and organic chemicals in the emulsion acting as follicular irritants.

Interdigital Maceration of the Feet.-Out of 126 operatives examined, $63(50 \%)$ revealed maceration of the interdigital clefts, the intensity of the reaction varying from a slight pallor to a complete denudation of the adjacent epidermal surfaces. The average case within this group exhibited, in addition to maceration, a variable degree of hyperidrosis and bromidrosis. Scrapings from the interdigital clefts of the 63 affected operatives were examined both microscopically and culturally and in only two cases was a specific pathogen found. This was Trichophyton rubrum in both cases.

The prevention of interdigital maceration constitutes a problem amongst operatives working under difficult atmospheric conditions. Clogs, loose-fitting footwear, and foot baths containing " penotrane" (Ward, Blenkisop \& Co.) have been tried with little success, although the latter did reduce the incidence of bromidrosis. Other methods of dealing with this problem are at present being investigated. 


\section{Discussion}

Siebert (1942), in an investigation of the possible industrial hazards in the manufacture of fibre glass, observed a mild irritative eruption, which disappeared within a few days, of the hands and forearms of new employees. Apart from this transient dermatosis, he failed to find any reference to any other new or unusual hazard in an exhaustive survey of the literature. These findings were confirmed by Sulzberger and Baer (1942), who considered that there was no direct evidence of sensitization and that the glass spicules were only superficially embedded. Schwartz and Botvinick (1943), although agreeing with the clinical findings, considered that sensitization could occur, not to the glass fibre but to the liquid binder, and that a degree of sensitivity developed in a considerable number of operatives. In this present survey no example of this transient irritation due either to mechanical causes or to contact with resin was noted, nor would such irritation have been expected as there were no new employees during the period of observation. Its occurrence was well known, and before the survey had been observed amongst new employees by one of us (D. A. M.).

A survey of the literature failed to reveal any reference to paronychia, a follicular eruption, or interdigital maceration of the feet, and we are of the opinion that the incidence is such as to warrant comment.

In view of the high incidence of maceration and associated hyperidrosis and bromidrosis, we expected there to be a correspondingly high incidence of tinea pedis, but this was not substantiated. In an attempt to determine the possible causative factors producing maceration, the type of footwear worn by the employees was examined. It was noted that maceration was present in $34 \%$ of those wearing wooden clogs and in $57 \%$ of those wearing leather boots or shoes. Examination of the leather footwear revealed a fine tenacious coating of resin and fibreglass sufficient to counteract the porosity of the leather. This purely mechanical occlusion in association with the warm atmosphere of work would in itself produce ideal conditions for the production of hyperidrosis and maceration from sweat retention. Although ventilation in clogs is minimal, they fit loosely and allow a steady flow of air over the feet.

The paronychia is, we suggest, directly associated with the implantation of glass splinters, which penetrate the skin in the region of the nail fold or pass between the nail fold and the nail, producing in both instances a foreign-body reaction. In three cases radiological evidence confirmed this hypothesis, which might well have been the cause in the remainder, the glass spicules having either been removed by the operator or worked themselves to the surface. The prevention of this condition is a most difficult problem, as the transparent and delicate nature of the glass filaments makes their removal a most difficult and intricate minor operation, yet this, in our opinion, is the only satisfactory solution. Consideration was given to the possibility of colouring the glass to facilitate its removal by the operative or industrial nurse, but this presented insurmountable technical difficulties. The use of industrial gloves fine enough to allow delicate movements was investigated, but again the combination of fibreglass and resin results in a markedly adhesive surface on the gloves. We consider that the immediate removal of the spicules by a trained and experienced nurse goes a long way towards reducing the incidence of paronychia.

Although the incidence of cutaneous lesions (69\%) may seem unduly high, it is pointed out that of the three clinical conditions noted in the survey only paronychia could be of such severity as to incapacitate the worker. Although their incidence was high the operatives paid little or no attention to their presence and seemed to accept them as a natural consequence of this type of work.

\section{Summary}

The manufacture of continuous filament glass fibre is described. A dermatological survey of 126 operatives was undertaken. A clinical assessment of the skin conditions observed in these operatives is given with special reference to paronychia of the fingers (eight cases), folliculitis of the feet, legs, forearms, and occasionally of the hands (14 cases), and maceration of the interdigital clefts of the toes (63 cases).

In view of the high incidence of maceration, a correspondingly high incidence of tinea pedis was expected, but not found; in only two of the 63 affected cases was fungus (Trichophyton rubrum) demonstrated.

Radiological evidence in three cases confirmed our view that paronychia is due to glass spicules in the nail fold.

We are greatly indebted to Mr. R. C. B. Anderson, manager of the Glasgow Division of Fibreglass Ltd., and his staff for their wholehearted cooperation in this investigation. We would also like to express our thanks to Dr. James Somerville, Department of Dermatology, Western Infirmary, Glasgow, for his advice and helpful criticism.

\section{REFERENCES}

Schwartz, L., and Botvinick, I. (1943). Industr. Med., 12, 142. Siebert, W. J. (1942). Ibid., 11, 6

Sulzberger. M. B., and Baer, R. L. (1942). Ibid., 11, 482. 